\title{
Experimental Renal Disease Induced by DNA-Anti-DNA Immune Complexes
}

\author{
Pier Giorgio Natali and Eng M. Tan \\ From the Division of Allergy and Immunology and the Department of \\ Experimental Pathology, Scripps Clinic and Research Foundation, \\ La Jolla, California 92037
}

A в S T R A C T Rabbits immunized with ultraviolet-irradiated DNA (UV-DNA) produced high titers of serum antibody. This experimental model was studied to determine if injection of antigen (UV-DNA) intravenously into immunized animals would induce glomerulonephritis and proteinuria. Proteinuria was observed several days after the start of daily intravenous injections into immunized animals and was sustained as long as injections were continued, but fell to normal values after stopping antigen administration. The kidneys showed glomerulitis sometimes associated with focal proliferative lesions, and immunofluorescence showed rabbit Ig and C3 in glomeruli. By electron microscopy, electron-dense subendothelial deposits were seen. Sucrose density gradient analyses of sera immediately after antigen injections suggested the presence of immune complexes of DNA and antibody since both heavy sedimenting and 7S Ig were detected. After digestion with deoxyribonuclease rabbit Ig could be found only in the $7 \mathrm{~S}$ sedimenting fractions. Intravenous injection of UV-DNA into normal, nonimmune animals did not produce heavy sedimenting Ig or abnormal sedimentation patterns. These studies with an experimental model might provide insight into pathogenetic mechanisms operating in systemic lupus erythematosus where the importance of DNA-anti-DNA immune complexes have been documented. The studies suggested that gradual accumulation of DNA immune complexes in glomeruli might be one mechanism causing renal functional abnormalities.

This is Publication No. 526 from the Department of Experimental Pathology, Scripps Clinic and Research Foundation, La Jolla, Calif. tion.

Dr. Tan is a Senior Investigator, The Arthritis Founda-

Received for publication 22 July 1971 and in revised form 11 October 1971.

\section{INTRODUCTION}

Considerable knowledge has been accumulated on antinuclear antibodies in the sera of patients with systemic lupus erythematosus (SLE) ${ }^{1}$ and on the role of these antibodies in production of tissue injury. There is substantial evidence to show that antibodies to native deoxyribonucleic acid (DNA) participate in pathogenetic mechanisms leading to the kidney disease seen in SLE. Earlier clinical observations stressed that antibodies to DNA were frequently present in the sera of patients with severe forms of the disease or in patients who were in clinical relapse $(1,2)$. More recent studies showed that free circulating antigen (DNA) could be detected in sera of patients with SLE and that in certain instances DNA was detected sequentially after disappearance of antibody to DNA (3). These observations which have been confirmed in recent studies $(4,5)$ strongly suggested that immune complexes were in volved in the kidney disease of SLE, since earlier immunohistochemical studies showed deposits of $\gamma$-globulin and complement distributed along the glomerular basement membrane in a lumpy fashion (6), very similar to the kidney lesions seen in experimental serum sickness (7). More direct proof for this pathogenetic mechanism has been the demonstration that antibodies with antinuclear specificities could be eluted from diseased SLE kidneys (8-10), and, more important, that a nuclear antigen, native DNA, was present on the glomerular basement membrane (10). Using antisera to nucleosides, it has been reported that nucleic acid metabolites were present in the glomeruli of SLE kidneys (11), and presumably that denatured DNA and antibody might be

${ }^{1}$ Abbreviations used in this paper: BSA, bovine serum albumin; DNA, deoxyribonucleic acid; PAS, periodic acidSchiff; PBS, phosphate-buffered saline; SLE, systemic lupus erythematosus. 
another antigen-antibody complex involved in nephritis. Evidence for the latter system is not as complete as that for native DNA, since there has been no documentation of denatured DNA in serum nor reports of relationship between antibodies to denatured DNA and disease activity.

The conditions which control the formation of immune complexes involving DNA are not known, and the actual observation of nephrotoxicity of such complexes has not been experimentally demonstrated. Such studies would be feasible if antibodies to native DNA could be induced in experimental animals. Native DNA, however, appears to be a poor antigen and attempts to induce antibodies to it in this and other laboratories have been unsuccessful. Native DNA is altered photochemically by ultraviolet (UV) rays with the formation of intra-strand dimers or polymers of adjacent thymines. Irradiated DNA is highly antigenic and antibodies to DNA photoproducts can be readily induced in rabbits $(12,13)$. Irradiated DNA, although possessing the photochemical alterations described, still maintained the immunological properties of native, double-strand DNA since it reacted with SLE sera containing antibodies to native DNA but not with other sera containing antibodies to denatured, single-strand DNA (13).

In the present study, rabbits were immunized with UV-irradiated DNA until high titers of circulating antibodies were obtained. When this was achieved, UVirradiated DNA was injected intravenously in a concentration calculated to result in antigen excess in circulating blood. Immune complexes of DNA and antibody were demonstrated in the circulation of these animals for short periods after antigen administration. After repeated injections, the animals developed renal disease which was characterized by proteinuria and fixation of $\boldsymbol{\gamma}$-globulin and complement on glomerular basement membranes.

\section{METHODS}

Preparation of animals with circulating antibodies to $U V$ $D N A$. Native calf thymus DNA (Worthington Biochemical Corp., Freehold, N. J.) was irradiated with UV according to a procedure described previously (13). Briefly, DNA at $500 \mu \mathrm{g} / \mathrm{ml}$ in phosphate $(0.01 \mathrm{M})$-buffered saline (PBS), $\mathrm{pH}$ 7.0, was irradiated with a G30T8 germicidal lamp (General Electric Co., Schenectady, N. Y.). When irradiated DNA solutions were complexed with methylated serum albumin according to Plescia, Braun, and Palczuk (14), a fine suspension was obtained which was homogenized in equal volumes of complete Freund's adjuvant. New Zealand albino rabbits were injected intramuscularly with $2 \mathrm{ml}$ of this mixture (containing $500 \gamma$ UV-DNA) weekly for 4 wk. 7 days after the last injection, antibodies to UV-DNA were detected in the sera. These antibodies were capable of reacting with UV-DNA by precipitation and complement fixation as reported previously (13) and titers of antibodies as determined by an immunofluorescent method de- scribed below were present at serum dilutions ranging from $1 / 256$ to $1 / 1024$.

Intravenous injections of antigen (UV-DNA). The objective of these experiments was to inject antigen (UVDNA intravenously into previously immunized rabbits in order to study factors which influenced the formation of immune complexes and renal disease. For this purpose, UVDNA dissolved in PBS was given daily in a single injection intravenously. The doses of UV-DNA were calculated by determining the amount of antigen required to reach equivalence in quantitative precipitin reactions (15) with sera from immunized animals. $10 \%$ of body weight was arbitrarily taken to represent the animal's antibodycontaining fluid volume, and the total amount of antigen given daily varied between 2 to 6 times equivalence. Large amounts of antigen (UV-DNA) were required in the initial injection in order to reach antigen excess, but after this initial injection, subsequent antigen injections were usually $1 / 5$ to $1 / 10$ of the first, since they were adjusted according to changes in the levels of precipitating antibody. As will be described in detail later, it was found that daily injections were necessary because UV-DNA disappeared rapidly from the circulation after each injection. Rabbits treated in this manner were kept in metabolic cages, urines were collected for studies, and kidney biopsies were performed at the end of the study or when consistent proteinuria was detected. Protein determinations in urines were performed by a sulfosalicylic acid method (16). Normal, untreated rabbits did not excrete more than $10 \mathrm{mg} / 24 \mathrm{hr}$.

Methods to detect antibody, antigen, and immune complexes. Indirect immunofluorescence was a sensitive and specific method for detecting antibody to UV-DNA either in serum or urine. The substrate consisted of UV-irradiated sections of frozen mouse kidney cut in a cryostat. Irradiation with UV caused DNA photoproducts to be formed in the cell nuclei of tissue sections and rabbit serum or urines with antibodies to UV-DNA reacted only with nuclei of irradiated sections but not with that of unirradiated sections. Details of the immunofluorescent method have been reported previously (13). This method was used throughout to detect and semiquantitatively estimate the presence of antibodies to UV-DNA in serum and urine.

Detection of antigen was by immunodiffusion in $0.4 \%$ agarose (17) against serum from a rabbit with a high titer of antibodies to UV-DNA. This antiserum was capable of detecting $4 \mu \mathrm{g}$ UV-DNA per $\mathrm{ml}$ serum or urine.

Sucrose density gradient analysis was employed (18) to determine if immune complexes were present in serum after injection of UV-DNA into immunized animals. A $10-40 \%$ continuous gradient of sucrose was employed with centrifugation at $35,000 \mathrm{rpm}$ for $18 \mathrm{hr}$ in a Beckman SW-50.1 swinging bucket rotor. Fractions were collected from the bottom of the tube. Gamma globulin in the fractions was detected by immunodiffusion against sheep antiserum to rabbit. Ig. This antiserum had been shown to give a single precipitin line in the $\gamma$-region against rabbit serum by immunoelectrophoresis. Some sera which showed Ig sedimenting as heavy material were digested with pancreatic deoxyribonuclease (Worthington Biochemical Corp.) to determine if Ig might be complexed with UV-DNA. Digestion was accomplished by adding $20 \mu \mathrm{g}$ deoxyribonuclease to $0.1 \mathrm{ml}$ serum and incubating at $37^{\circ} \mathrm{C}$ for $3 \mathrm{hr}$. Digestion was stopped by chilling the mixture to $4^{\circ} \mathrm{C}$.

Studies of kidney tissues. Samples of renal tissue from rabbits were obtained from biopsies performed under anesthesia using clean, but not sterile, conditions. Tissues were 
TABLE I

Renal Lesions and Proteinuria after Intravenous Antigen Injections in Immunized Animals

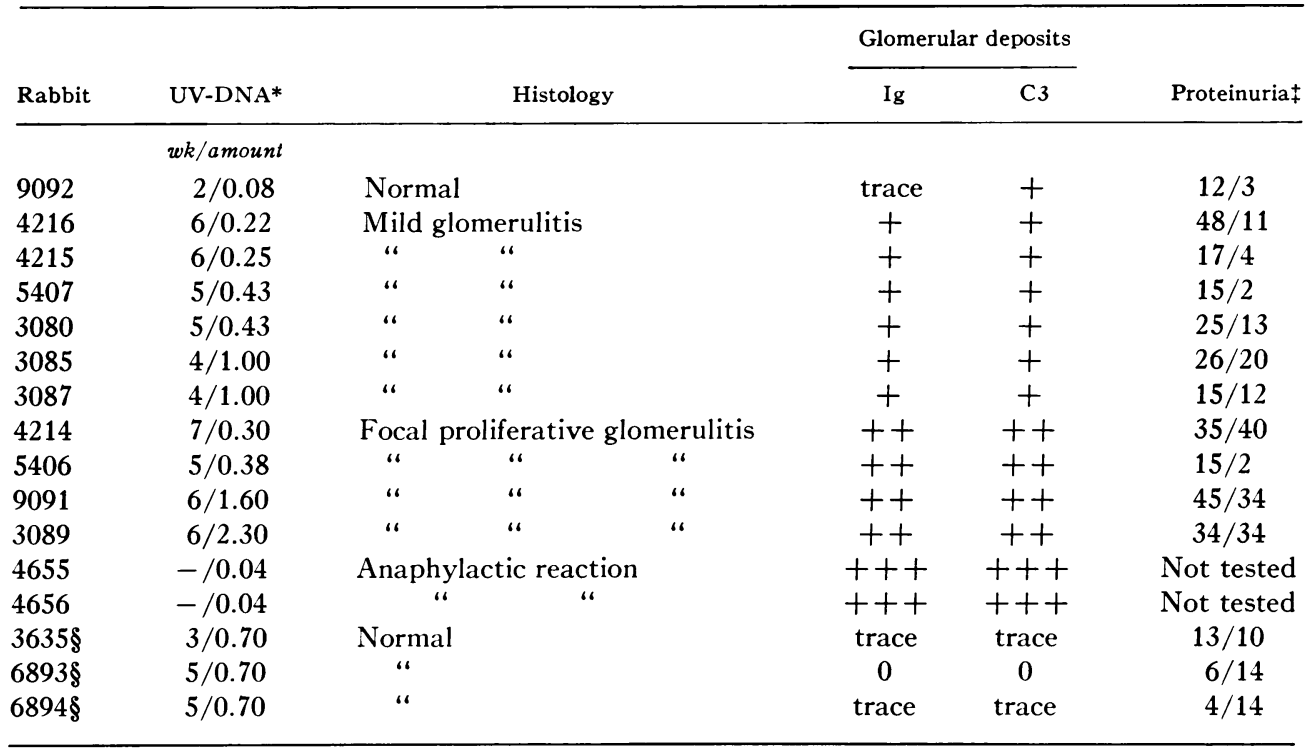

* Weeks of treatment/total grams UV-DNA given intravenously.

$\ddagger$ Average proteinuria $\mathrm{mg} / 24 \mathrm{hr}$ per number of determinations.

$\S$ Nonimmunized normal rabbits given intravenous antigen injections.

studied for routine histology with hematoxylin-eosin and periodic acid-Schiff (PAS) stains and by immunofluorescence and electron microscopy. For immunofluorescence, biopsy specimens were embedded in OCT compound (Ames Co., Elkhart, Ind.) and snap-frozen in liquid nitrogen. Sections of $4 \mu$ thickness were cut in a cryostat and washed two times for $5 \mathrm{~min}$ each in PBS to get rid of unbound serum proteins. They were then reacted directly with fluorescein-conjugated antiserum to rabbit $\mathrm{Ig}$, rabbit $\mathrm{C} 3$, and rabbit fibrinogen. Antiserum to rabbit Ig was the same as that described above, anti-rabbit $\mathrm{C} 3$ was produced according to Mardiney and Müller-Eberhard (19) and rabbit fibrinogen for immunization prepared by the method of Kekwick, MacKey, Nance, and Record (20). All antisera were labeled with fluorescein isothiocyanate according to Wood, Thompson, and Goldstein (21). Fluorescein-conjugated antiserum to UV-DNA was prepared in the same manner with rabbit antiserum.

Clearance of $D N A-{ }^{s} H$ and $U V-D N A-{ }^{s} H$ from circulation. DNA ${ }^{8} \mathrm{H}$ from calf thymus was purchased from Worthington Biochemicals Corp. It was reported to have specific activity of $75 \mu \mathrm{Ci} / \mathrm{mg} \mathrm{DNA}$ and that $85 \%$ was in native form. Aliquots of labeled DNA were irradiated with UV as described above. Labeled native and UV-DNA were mixed with large excess of carrier unlabeled native and UV-DNA respectively so that the final mixtures contained a total of $40 \mathrm{mg}$ DNA giving total counts of $14 \times 10^{5}$ per $\min$ in a liquid scintillation spectrometer. This amount of DNA was equivalent to the first intravenous injection of antigen in animals which were receiving daily antigen injections. The mixtures of labeled DNA and carrier were injected intravenously into normal rabbits and rate of disappearance of radioactivity from serum was followed by periodic sampling of blood over a period of $4 \mathrm{hr}$.

\section{RESULTS}

Histopathology. Table I depicts the findings in $13 \mathrm{im}$ munized rabbits which were given intravenous injections of UV-DNA and 3 unimmunized normal rabbits treated in a similar manner. Total duration of treatment and total amount of UV-DNA given are presented in the second column. With the exception of one animal (9092), others in the immunized group showed glomerular pathology varying from mild glomerulitis to focal proliferative glomerulonephritis. Glomerulitis was characterized by involvement of mesangial areas with accumulation of PAS-positive material in the axial regions. An example of focal proliferative glomerulitis is shown in Fig. 1 for rabbit 4214 compared with glomerulus from a normal rabbit kidney. Proliferation of cells resulted in narrowing of capillary lumens in a number of focal areas within the glomerulus. In two rabbits significant polymorphonuclear infiltration was present in the glomeruli in addition to focal proliferative changes. In two other animals $(4655,4656)$ the first intravenous injection of antigen produced fatal generalized anaphylactic-like reactions characterized by severe respiratory embarrassment and convulsions. On autopsy, subpleural hemorrhagic effusions were present and histologically there were PAS-positive thrombi in vessels of the lungs, kidneys, and liver. The majority of the immunized animals did not suffer this reaction and studies could be carried out for several weeks. Three non- 


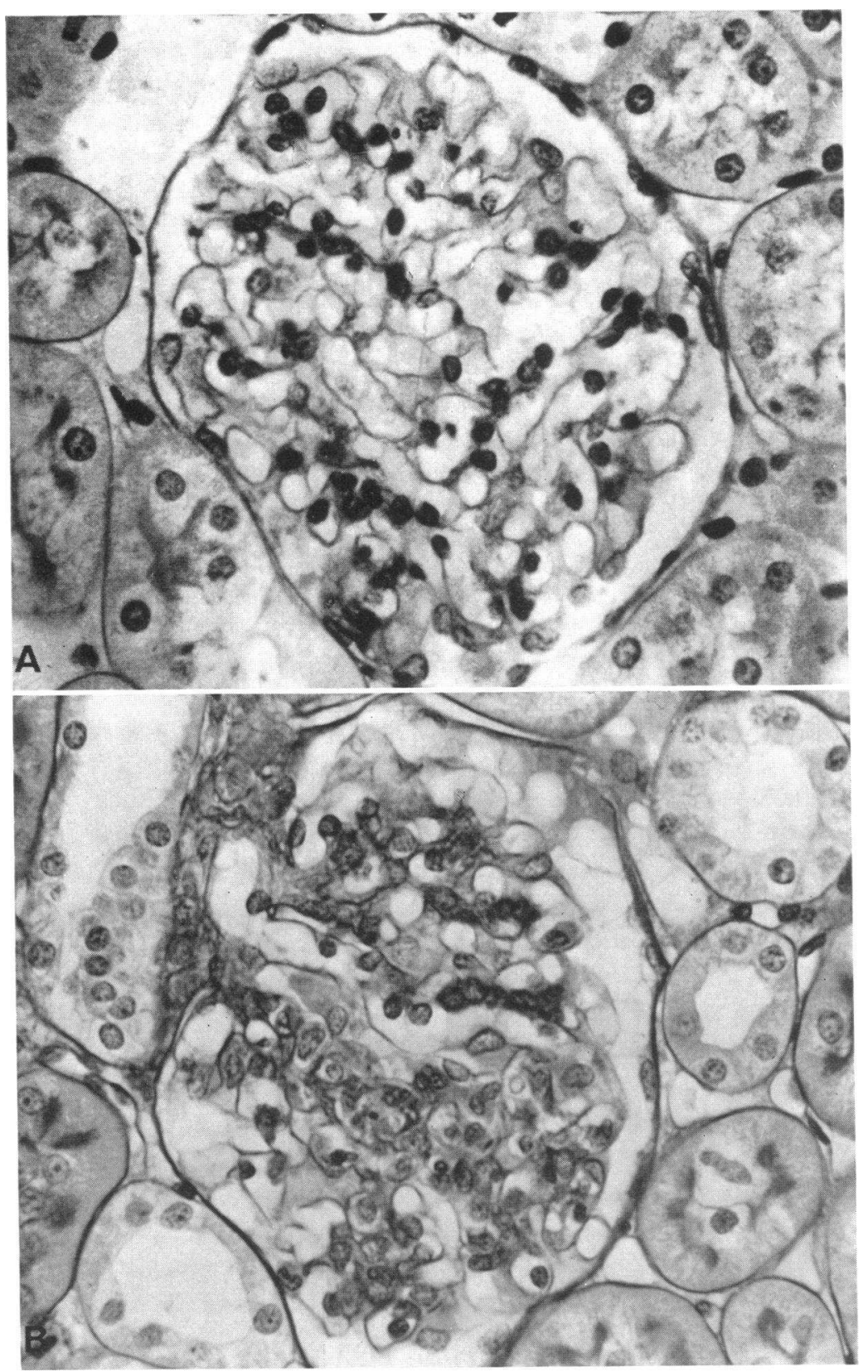

FIGURE 1 Glomerulus showing focal proliferative glomerulitis from rabbit 4214 (B) compared with glomerulus from normal rabbit (A). Proliferation of mesangial and endothelial cells (B) has resulted in obliteration or narrowing of the capillary lumen in many areas of the glomerulus. (PAS stain, $\times 600$ )

immunized normal rabbits served as controls and were given daily intravenous antigen injections in duration and amount equivalent to that of immunized animals. No abnormal renal pathology was present in the kidneys but one animal (3635) showed a slightly increased proteinuria with an average of $13 \mathrm{mg} / 24 \mathrm{hr}$.

By immunofluorescence all animals which developed excessive proteinuria showed fine granular deposits of rabbit Ig and $\mathrm{C} 3$ bound to glomeruli (Table I and Fig. $2)$. The deposits were present in mesangial areas as well as peripheral glomerular capillary loops. Weak staining for rabbit fibrin/fibrinogen was detected in the glomeruli of only one rabbit (9091). In the two animals that had generalized anaphylactic reactions, $\mathrm{Ig}$ and $\mathrm{C} 3$ were 

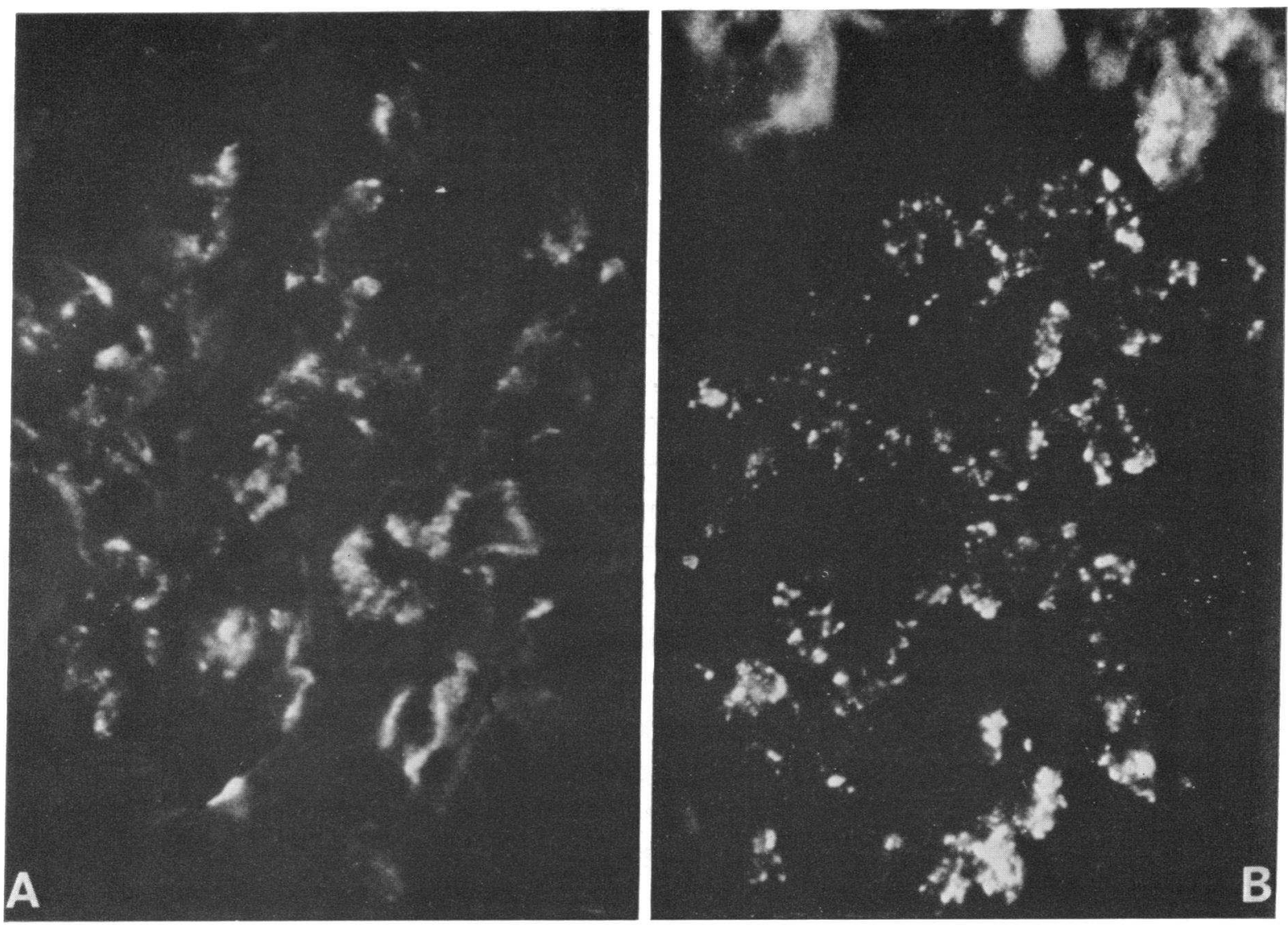

FIGURE 2 Immunofluorescent staining for rabbit Ig (A) and C3 (B) in glomeruli of kidney biopsy obtained from rabbit 4214. Granular deposits of $\mathrm{Ig}$ and $\mathrm{C} 3$ were located in both mesangial areas and peripheral capillary loops $(\times 650)$.

widely deposited in blood vessels of lung, kidney, spleen, and pancreas with deposits sometimes completely obliterating the lumen of the vessels. Of the three control rabbits which had not been previously immunized, two showed trace deposits of $\mathrm{Ig}$ and $\mathrm{C} 3$ in the glomeruli. These animals did not have antibody to UV-DNA before the start of the experiments but at the conclusion of the experiments rabbit 3635 had an antibody titer of $1: 4$ by immunofluorescence, rabbit 6894 a titer of $1: 8$, and rabbit 6893 was still negative.

Electron microscopy of kidney biopsies were pertormed on two rabbits with mild glomerulitis and three with focal proliferative glomerulonephritis. In the two animals with mild glomerulitis $(3085,3087)$, electrondense deposits were detected only in the mesangium, whereas in the three animals with focal proliferative glomerulonephritis (3089, 9091, and 4214), electron-dense material was also present on the subendothelial aspect of the glomerular basement membrane as shown in Fig. 3. A fewer number of subepithelial electron-dense deposits were detected as well. Fusion of the epithelial foot processes was also noted (Fig. 3) and in rabbit
4214 several polymorphonuclear leukocytes were present in the capillary lumens in close contact with endothelial cytoplasm.

Characteristics of proteinuria. Before antigen was injected, base line urine protein was determined for each animal for at least 3 days. All animals reported in Table I had base line proteinuria of less than $10 \mathrm{mg}$ / $24 \mathrm{hr}$. Generally, increased proteinuria occurred after a lag period of at least $1 \mathrm{wk}$ of daily antigen injections and the values in the last column represent the average of the increased proteinuria detected. Animals with more severe renal disease as shown by routine histology and immunofluorescence had larger amounts of proteinuria, but there was no direct relationship to the total DNA given.

The extent and duration of proteinuria during the course of the experiment is shown for two rabbits in Fig. 4. In both animals, 3089(a) and $4214(b)$, the onset of abnormal proteinuria did not occur immediately after intravenous injections. In $3089(a)$ it took about 5-7 days before proteinuria of $20 \mathrm{mg}$ was observed, and in $4214(b)$ it took more than 30 days before significantly 


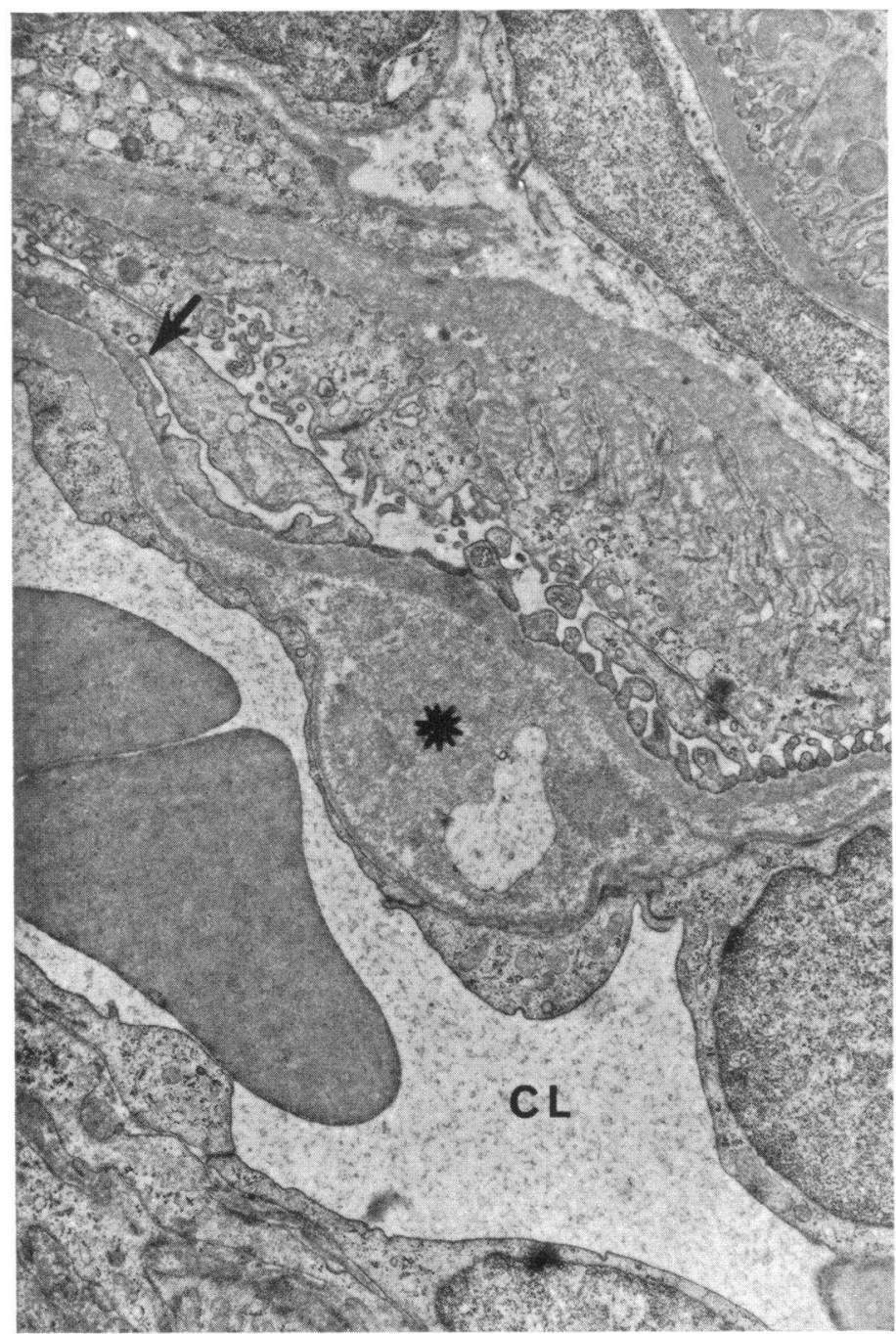

FigURE 3 Electron micrograph of kidney biopsy of rabbit 4214 obtained when the animal showed proteinuria $(42 \mathrm{mg} / 24 \mathrm{hr})$. Electrondense material is present on subendothelial aspect of the glomerular basement membrane in the form of a large deposit (asterisk). Fusion of the epithelial foot processes is also present (arrow). CL, capillary lumen. (Lead citrate stain, $\times 10,800$ )

elevated proteinuria was present. In these as well as other rabbits, when proteinuria developed it increased gradually over the duration of the experiment. Antigen injections were stopped after the first course of 22 days in animal 3089 $(a)$, and it was given a booster immunization of UV-DNA in complete Freund's adjuvant. This animals was then given a second course of intravenous antigen and the onset of increased proteinuria was more rapid than previously. A further characteristic observed in the animals in this study is also illustrated in Fig. 4. After cessation of intravenous antigen injections, the abnormal proteinuria returned towards normal values. Chronic proteinuria was not observed in these animals after cessation of the acute experiments.

The urines of three rabbits with increased protein excretion were analyzed for presence of $\gamma$-globulin and by immunofluorescence for antibody activity. These urines and that of normal rabbits were concentrated 20 times and in immunoelectrophoresis it could be clearly demonstrated that urines from the experimental animals contained large amounts of $\gamma$-globulin which was absent or barely detectable in concentrated normal rabbit urine. Furthermore, concentrated rabbit urines from two of three experimental animals which were studied 

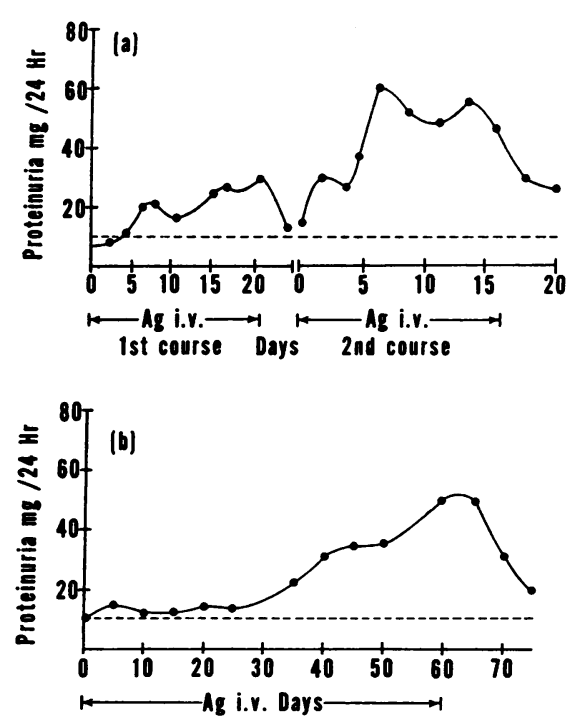

FIGURE 4 Characteristics of proteinuria observed in hyperimmune rabbits after intravenous injections of antigen. Rabbit 3089 represented in (a) and 4214 in $(b)$. Note delayed onset of proteinuria above base line values denoted by horizontal broken line. Proteinuria fell towards normal values after cessation of intravenous antigen injections. Rabbit 3089 was given two courses of intravenous antigen injections separated by a period when it received a booster immunization of UV-DNA in complete Freund's adjuvant in order to raise serum antibody level.

showed antibody activity to UV-DNA by immunofluorescence. Concentrated urines from two nonimmunized rabbits given intravenous antigen alone did not contain antibody to UV-DNA.

Sucrose density gradient studies. Since the experiments were designed to cause the formation of immune complexes in vivo, rabbit sera were analyzed for such complexes by centrifugation in a linear sucrose gradient of $10-40 \%$. Sera from five rabbits were examined in this manner and representative results are reported for two animals. Rabbit 3087 was given UV-DNA equal to twice antigen-antibody equivalence $(8 \mathrm{mg})$ shown in Fig. 5, and 6 times equivalence (24 mg) shown in Fig. 6. Sera were obtained immediately before and at various times after intravenous antigen injection and studied the same day in sucrose gradient centrifugation. Fractions obtained at the end of centrifugation were analyzed for rabbit $\gamma$-globulin by immunodiffusion and fractions containing $\gamma$-globulin are represented by solid black bars. The significant features were the appearance of heavy sedimenting protein within minutes after injection of antigen. Rabbit immunoglobulin which sedimented in the region of the 7S marker before antigen injection was detected up to and beyond the 19S markers after injection. Comparison of the 10-min panels shows that the larger amount of antigen (6 times equiva-
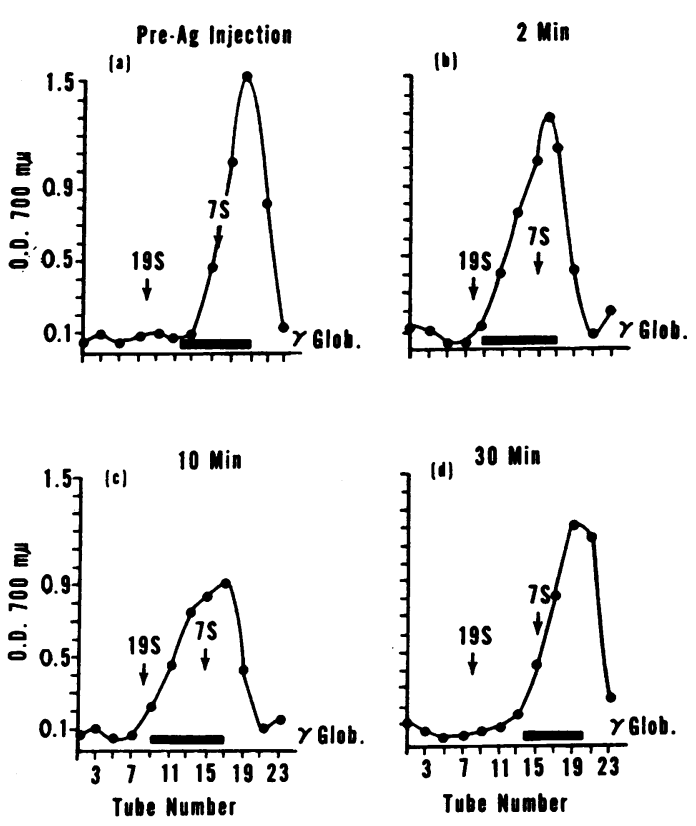

Figure 5 Analysis by sucrose gradient ultracentrifugation of sera after intravenous injection of UV-DNA into immunized rabbit (3087). Bottom of gradient is at left, top of gradient at right. $8 \mathrm{mg}$ UV-DNA (2 times equivalence) was given. Rabbit Ig is represented by horizontal black bars and 19S and 7S markers are depicted. Note immediate appearance of heavy sedimenting $\mathrm{lg}$ at 2 and $10 \mathrm{~min}$ and its disappearance at $30 \mathrm{~min}$.

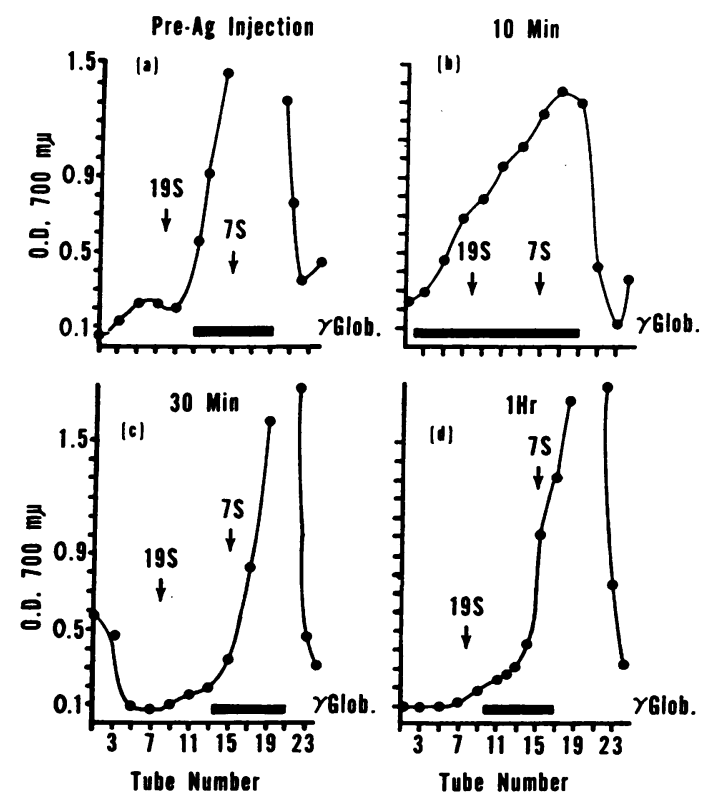

FIgURE 6 Same rabbit as in Fig. 6 given $24 \mathrm{mg}$ UV-DNA (6 times equivalence). $10 \mathrm{~min}$ after intravenous injection, there was a large amount of heavy sedimenting Ig which had disappeared in $30 \mathrm{~min}$.

DNA-anti-DNA Immune Complexes 


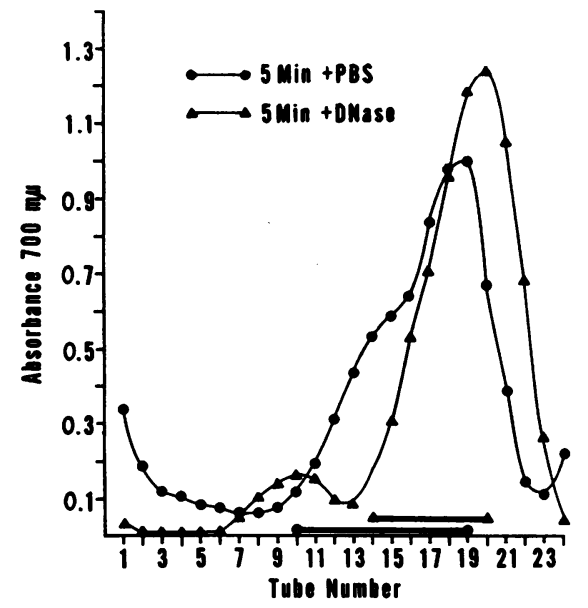

FIgURe 7 Sucrose gradient ultracentrifugation analysis of rabbit 4216 serum treated with PBS (-—) and with deoxyribonuclease $(\boldsymbol{\Delta} \boldsymbol{\Delta})$ in vitro. Serum was drawn 5 min after injection of UV-DNA intravenously. Deoxyribonuclease-treated serum showed shifting of the shoulder of heavy sedimenting Ig to lighter portions of gradient. Rabbit $\gamma$-globulin was determined by immunodiffusion and is represented by solid bars at the bottom of sedimentation patterns.

lence) produced more heavy sedimenting protein and $\gamma$-globulin at the bottom of the gradient than the smaller amount of antigen. A further feature of these studies was the rapid disappearance of heavy sedimenting $\gamma$-globulin and within $30 \mathrm{~min}$ after antigen injection, the sedimentation characteristics of serum returned to that of preantigen injection.

The appearance of large quantities of heavy sedimenting $\gamma$-globulin as illustrated in the $10 \mathrm{~min}$ panel of Fig. 6 might be thought to be due to the great excess of antigen ( 6 times equivalence) injected. This, however, was not the case in another rabbit (3085) which also received 6 times equivalence of antigen but showed changes more similar to that illustrated in Fig. 5. Other animals analyzed in this manner similarly showed moderate amounts of heavy sedimenting $\gamma$-globulin within minutes after antigen injection followed by rapid disappearance of this heavy material. As control for these density gradient studies, one nonimmunized normal rabbit was given $50 \mathrm{mg}$ UV-DNA intravenously to determine if UV-DNA might for some reason complex with normal rabbit Ig to cause the appearance of the heavy sedimenting Ig shown in Figs. 5 and 6. Samples of sera were analyzed at 2, 10, 30, and $60 \mathrm{~min}$ after intravenous injection and the sedimentation patterns did not differ from that of preinjection serum.

The sera of two rabbits (4216 and 3087) in which heavier sedimenting $\boldsymbol{\gamma}$-globulin appeared subsequent to antigen injection were subjected to treatment with pancreatic deoxyribonuclease to determine if such pro- cedure would alter the sedimentation pattern in sucrose gradient ultracentifugation.

An example is shown in Fig. 7 where serum from rabbit $4216,5 \mathrm{~min}$ after intravenous injection of UV-DNA, was incubated with deoxyribonuclease with an aliquot treated with PBS in the same manner. The results showed that deoxyribonuclease treatment abolished the heavier sedimenting shoulder in the region of tubes 10-15 and that rabbit $\gamma$-globulin now was detectable only in the lighter sedimenting region of the gradient between tubes 14 and 20.

Kinetics of elimination of DNA from normal and immunized animals. The sucrose gradient sedimentation studies provided evidence for the presence of immune complexes in serum and showed that these complexes were rapidly cleared from the circulation. The experiment shown in Fig. 8 was performed in a rabbit which had high titers of antibody to UV-DNA but had not previously received any intravenous injection of antigen. $96 \mathrm{mg}$ of UV-DNA which was equal to 6 times antigenantibody equivalence was given intravenously at time zero. The changes in antibody titer were determined by immunofluorescence and the presence of free UV-DNA in circulation by immunodiffusion. Antibody disappeared rapidly after antigen injection and remained undetectable for the 1 st $\mathrm{hr}$ but reappeared by the $2 \mathrm{nd} \mathrm{hr}$ and continued to increase in amount thereafter. UV-DNA was detected in the circulation only for the first $60 \mathrm{~min}$ after antigen injection and was not detected in subsequent bleedings.

These studies raised the possibility that the rapid clearance of UV-DNA might in some way be related to more rapid natural catabolism of UV-DNA than native DNA, and this problem was investigated. One normal rabbit received $40 \mathrm{mg}$ of native DNA which contained native $\mathrm{DNA}-{ }^{3} \mathrm{H}$ and another rabbit received the

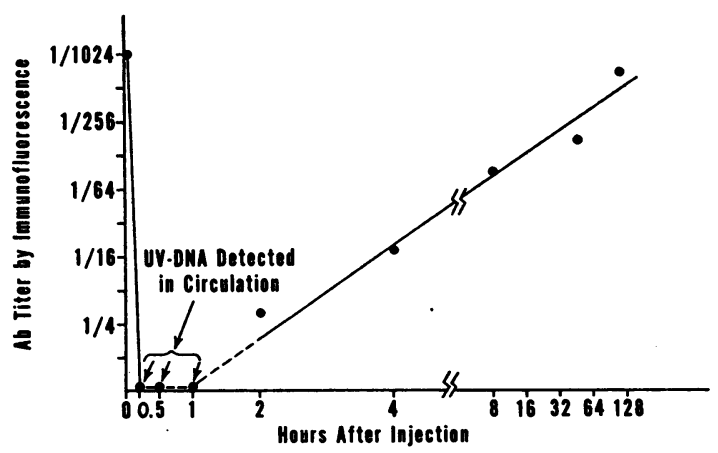

FIGURE 8 Clearance of UV-DNA from circulation of immunized rabbit. After intravenous injection of $96 \mathrm{mg} \mathrm{UV}$ DNA (6 times equivalence) antibody was not detectable in blood for the 1st $\mathrm{hr}$ and circulating UV-DNA was detected for the $1 \mathrm{st} 30 \mathrm{~min}$. Free DNA was not detected after this and antibody reappeared between the 1 st and $2 \mathrm{nd} \mathrm{hr}$. 
same amount of UV-DNA with UV-irradiated DNA- ${ }^{8} \mathrm{H}$. The radioactive antigens were present in trace amounts and gave total counts of $14 \times 10^{8} \mathrm{cpm}$ in each specimen. The results depicted in Fig. 9 show that native DNA and UV-DNA were eliminated from the circulation of these rabbits at rates that could not be distinguished from each other. Less than $10 \%$ of total radioactivity remained in the circulation within 60 min after injection.

\section{DISCUSSION}

In the absence of an experimental animal in which antibodies to native DNA could be elicited de novo, these studies were performed in rabbits with circulating antibodies to UV-DNA. In some respects, these systems might be analogous. UV-irradiated DNA, as described earlier, behaved immunochemically like double-strand DNA. Antibodies to UV-DNA have been characterized concerning their specificities $(12,22)$ and antigenic determinants were shown to be photochemically converted dimers or polymers of adjacent thymines on the homologous DNA strand. In the studies of Stollar, Levine, Lehrer, and Van Vunakis (23) concerning specificities of antibodies to DNA in human sera, the optimum antigenicity as determined by inhibition of complement fixation consisted of specific oligonucleotides of four or five nucleotide lengths. In both human disease and the current experimental models, therefore, antibodies reacted with their respective DNA not throughout the molecule but at certain regions where nucleotide sequences coincided with antibody specificity.

In the present study, the important features of the renal disease produced by immune complexes of UVDNA and antibody were that renal disease was reversible and that glomerular histopathology and proteinuria were relatively mild. In 2 of 13 animals, anaphylactic-like reactions occurred and in these animals, immune complexes contributing to the thrombotic lesions present in blood vessels could be demonstrated by immunofluorescent staining for $\gamma$-globulin, complement, and UV-DNA. The reason for the difference in reaction to injected antigen in these two rabbits is not immediately apparent. In other rabbits surviving intravenous antigen injections, the renal deposits of $\gamma$-globulin and complement were probably composed of immune complexes since these complexes were demonstrated in the circulation. However, it was not possible to stain the deposits directly with fluorescein-conjugated antibody to UVDNA. One reason might be that the amounts of UVDNA were below the capacity of detection by direct immunofluorescence, since $\gamma$-globulin deposits were relatively small. The presence of trace deposits of rabbit Ig and C3 in two control animals might also be due to immune complexes since these animals had detectable circulating antibody at the end of the course of intra-

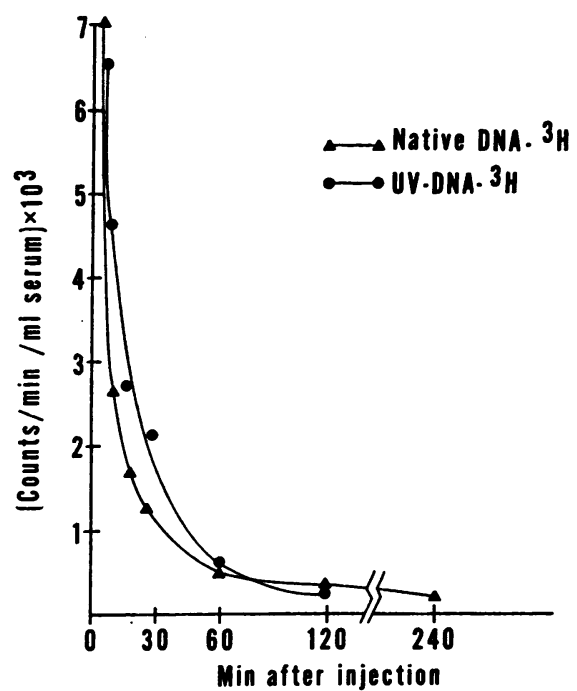

Figure 9 Clearance of tritium-labeled DNA from circulation of normal nonimmunized rabbits. One animal was given native DNA and the other UV-irradiated DNA intravenously. Both types of DNA were cleared at similar rates and less than $10 \%$ remained in the circulation after $60 \mathrm{~min}$.

venous antigen injections. The results further suggested that UV-DNA uncomplexed to carrier-methylated BSA was immunogenic. However, the titers of antibody were very low compared with those of animals immunized with UV-DNA complexed to methylated BSA.

Further factors should be considered in relation to the glomerular histopathology and proteinuria observed in these animals. After injection of excess antigen, antibody disappeared from the circulation for not longer than $1 \mathrm{hr}$ and by sucrose gradient ultracentrifugation, immune complexes were detected in the circulation for not longer than $30 \mathrm{~min}$. A factor to be considered is that UV-DNA is a large molecule with multiple antigenic determinant sites and its complexing with antibody would be expected to result in relatively large immune complexes, as was demonstrated in some of these studies. Large immune complexes are cleared from the circulation very rapidly as has been reported in several recent studies (24-26). However, the extremely rapid clearance of injected antigen was not entirely due to circulating antibody since UV-DNA or native DNA injected into normal animals were both rapidly removed from the circulation. The latter finding in rabbits is analogous to that in mice where rapid catabolism of injected DNA in nonimmunized animals has been observed (27-29). The very short duration of immune complexes in the circulation after a single antigen injection might account for the relatively mild renal disease observed and for the fact that there was a lag period before proteinuria was detected. This lag period might represent the time required for complex deposits 
to accumulate in sufficient amounts to cause functional renal abnormalities.

In the light of these experimental observations, certain features concerning spontaneous SLE in humans might be considered. It has been documented that free circulating DNA can be detected in the circulation of some patients for a number of days $(3,5,30)$. This abnormal finding has been observed not only in SLE but also in a few other disease states such as cholangiolitic hepatitis, lymphosarcoma, and carcinomatosis with liver metastases $(3,30)$. The presistence of DNA could be due to its constant release into the circulation, either because of endogenous tissue destruction or of exogenous origin from bacterial or viral organisms. Since circulating DNA in human disease has not been chemically characterized, this question cannot be definitely settled at this time. On the other hand, the persistence of DNA could be due to depressed catabolism. It has been shown that cellular elements of blood are rich in nuclease activity (31), and it is possible that a defect or deficiency of this enzyme might be responsible for this abnormality. A further factor to be considered is that inhibitors of deoxyribonuclease are present in blood and that increased concentrations of such inhibitors might play a role (32).

In the present studies, it was observed that animals hyperimmunized with UV-DNA and containing high titers of antibodies in the blood did not develop renal disease until immune complexes were formed in vivo by injection of antigen. This is consistent with observations in SLE where it has been shown that antinuclear antibodies by themselves were not pathogenic in vivo (33, $34)$ or cytotoxic to tissue culture cells in vitro $(35,36)$. The experimental observations reported here point to the need, however, for vigilance in the care of patients with SLE who have circulating antibodies to DNA, since small amounts and brief episodes of immune complex formation in the circulation might occur unnoticed. If accumulation of immune complexes in a target organ such as the kidney were allowed to continue, it might ultimately result in renal functional abnormalities.

\section{ACKNOWLEDGMENTS}

We wish to acknowledge the excellent technical assistance of Miss Maria Ashton.

This work was supported by Grants AM 12198 and AI 00214 from The National Institutes of Health.

\section{REFERENCES}

1. Seligmann, M. 1963. DNA antibodies. Arthritis Rheum. 6: 542 .

2. Friou, G. J. 1967. Antinuclear antibodies: diagnostic significance and methods. Arthritis Rheum. 10: 151.

3. Tan, E. M., P. H. Schur. R. I. Carr, and H. G. Kunkel. 1966. Deoxyribonucleic (DNA) and antibodies to DNA in the serum of patients with systemic lupus erythematosus. J. Clin. Invest. 45: 1732.

4. Schur, P. H., and J. Sandson. 1968. Immunological factors and clinical activity in systemic lupus erythematosus. N. Engl. J. Med. 278: 533.

5. Sharp, G. C., W. S. Irvin, R. L. LaRoque, C. Velez, V. Daly, A. D. Kaiser, and H. R. Holman. 1971. Association of autoantibodies to different nuclear antigens with clinical patterns of rheumatic disease and responsiveness to therapy. J. Clin. Invest. 50: 350 .

6. Vazquez, J. J., and F. J. Dixon. 1957. Immunohistochemical study of lesions in rheumatic fever, systemic lupus erythematosus, and rheumatoid arthritis. Lab. Invest. $6: 205$.

7. Dixon, F. J., J. J. Vazquez, W. O. Weigle, and C. G. Cochrane. 1958. Pathogenesis of serum sickness. Arch. Pathol. 65 : 18.

8. Freedman, P., and A. S. Markowitz. 1962. Isolation of antibody-like gamma globulins from lupus glomeruli. Brit. Med. J. 1: 1175.

9. Krishnan, C., and M. H. Kapan. 1967. Immunopathologic studies of systemic lupus erythematosus. II. Antinuclear reaction of $\gamma$-globulin eluted from homogenates and isolated glomeruli of kidneys from patients with lupus nephritis. J. Clin. Invest. 46: 569.

10. Koffler, D., P. H. Schur, and H. G. Kunkel. 1967. Immunological studies concerning the nephritis of systemic lupus erythematosus. J. Exp. Med. 126: 607.

11. Andres, G. A., L. Accinni, S. M. Beiser, C. L. Christian, G. A. Cinotti, B. F. Erlanger, K. C. Hsu, and B. C. Seegal. 1970. Localization of fluorescein-labeled antinucleoside antibodies in glomeruli of patients with active systemic lupus erythematosus nephritis. J. Clin. Invest. 49: 2106.

12. Levine, L., E. Seaman, E. Hammerschlag, and H. Van Vunakis. 1966. Antibodies to photoproducts of deoxyribonucleic acid irradiated by ultraviolet light. Science (Washington). 153: 1666.

13. Tan, E. M., and R. B. Stoughton. 1969. Ultraviolet light alteration of cellular deoxyribonucleic acid in vivo. Proc. Nat. Acad. Sci. U. S. A. 62: 708.

14. Plescia, O. J., W. Braun, and N. C. Palczuk. 1964. Production of antibodies to denatured deoxyribonucleic acid (DNA). Proc. Nat. Acad. Sci. U. S. A. 52: 279.

15. Kabat, E. A., and M. M. Mayer. 1961. Experimental Immunochemistry. Charles C. Thomas, Publisher, Springfield, Ill. 22.

16. Kingsbury, F. B., C. P. Clark, G. Williams, and A. L. Post. 1926. The rapid determination of albumin in urine. J. Lab. Clin. Med. 11: 981.

17. Tan, E. M., and H. G. Kunkel. 1966. Characteristics of a soluble nuclear antigen precipitating with sera of patients with systemic lupus erythematosus. J. Immunol. 96: 464 .

18. Kunkel, H. G. 1960. Macroglobulins and high molecular weight antibodies. In The Plasma Proteins. F. W. Putnam, editor. Academic Press Inc., New York. 279.

19. Mardiney, M. R., and H. J. Müller-Eberhard. 1965. Mouse $\beta 1 \mathrm{C}$-globulin: production of antiserum and characterization in the complement reaction. J. Immunol. $94: 877$.

20. Kekwick, R. A., M. E. MacKay, M. H. Nance, and B. R. Record. 1955. The purification of human fibrinogen. Biochem. J. 60: 671 .

21. Wood, B. T., S. H. Thompson, and G. Goldstein. 1965. Fluorescent antibody staining. III. Preparation of flu- 
orescein-isothiocyanate labelled antibodies. J. Immunol. $95: 225$.

22. Natali, P. G., and E. M. Tan. 1971. Immunological detection of thymidine photoproduct formation in vivo. Radiat. Res. 46: 506.

23. Stollar, D., L. Levine, H. I. Lehrer, and H. Van Vunakis. 1962. The antigenic determinants of denatured DNA reactive with lupus erythematosus serum. Proc. Nat. Acad. Sci. U.S. A. $48: 874$.

24. Cochrane, C. G., and D. Hawkins. 1968. Studies on circulating immune complexes. III. Factors governing the ability of circulating complexes to localize in blood vessels. J. Exp. Med. $127: 137$.

25. Lightfoot, R. W., R. E. Drusin, and C. L. Christian. 1970. Properties of soluble immune complexes. J. Immunol. 105 : 1493.

26. Mannik, M., W. P. Avend, A. P. Hall, and B. C. Gilliland. 1971. Studies on antigen antibody complexes. I. Elimination of soluble complexes from rabbit circulation. J. Exp. Med. 133 : 713.

27. Bendich, A., T. Wilczok, and E. Borenfreund. 1965. Circulating DNA as a possible factor in oncogenesis. Science (Washington). 148: 374.

28. Tsumita, T., and M. Iwanaga. 1963. Fate of injected deoxyribonucleic acid in mice. Nature (London). 198: 1088.
29. Ledoux, L. 1965. Uptake of DNA by living cells. Progr. Nucl. Acid Res. Mol. Biol. 4: 231.

30. Carr, R. I. 1969. DNA antibodies and DNA in serum. $\mathrm{Ph} . \mathrm{D}$. Thesis. The Rockefeller University, New York.

31. Gupta, S., and R. M. Herriott. 1963. Nucleases and their inhibitors in the cellular components of human blood. Biochem. Biophys. Acta. 101: 88.

32. Frost, P. G., and P. J. Lachmann. 1968. The relationship of deoxyribonuclease inhibitor levels in human sera to the occurrence of antinuclear antibodies. Clin. Exp. Immunol. 3 : 447.

33. Marmont, A. M. 1965. The transfusion of active LE plasma into nonlupus recipients with a note on the LElike cell. Ann. N. Y. Acad. Sci. 124: 838.

34. Beck, J. S., C. L. Oakley, and N. R. Rowell. 1966. Transplacental passage of antinuclear antibody. Studies in infants of mothers with systemic lupus erythematosus. Arch. Dermatol. 93 : 656.

35. Rapp, F. 1962. Localization of antinuclear factors from lupus erythematosus sera in tissue culture. J. Immunol. 88: 732.

36. Ward, J. R., R. S. Cloud, and L. M. Turner, Jr. 1964. Non-cytotoxicity of "nuclear antibodies" from lupus erythematosus sera in tissue culture. Ann. Rheum. Dis. 23: 381 . 